\title{
Transurethral endoscopic retrograde pancreatography: a novel endoscopic technique to treat complications after pancreas transplantation
}

In patients with transplanted pancreas, early technical failure accounts for more than half of graft losses during the initial posttransplant period - a complication that necessitates graft pancreatectomy [1]. Failure rates for pancreas recipients in the United States approximate 5\%, with reoperative rates between $12 \%$ and $43 \%[2,3]$. Graft thrombosis is the leading cause of technical failure, followed by anastomotic leak, infection, pancreatitis, and bleeding. The etiology of transplant pancreas leak may be a failure of healing/ sealing of a pancreaticoenteric anastomosis, or a parenchymal disruption originating from the pancreatic ductal system [4]. Initial management of postoperative leaks involves percutaneous drainage. If clinical deterioration occurs, relaparotomy is mandatory [5]. Endoscopic retrograde pancreatography (ERP) offers pancreatic sphincterotomy and placement of pancreatic ductal stents, which are effective in treating pancreatic leaks. The postsurgical anatomy and its anastomosis with the bladder makes conventional endoscopic access impossible.

Our patient was a 34-year-old man who had received pancreatic and renal transplants for type 1 diabetes mellitus and end-stage renal disease. The pancreas was transplanted using a bladder drainage approach. On postoperative day 7 the patient complained of right lower quadrant abdominal pain and developed fever and leukocytosis. Computer tomography (CT) showed new-onset ascites, and peritoneal fluid analysis revealed significantly elevated amylase and lipase levels, but CT cystogram did not reveal any microperforaton or staple line leak.

Initial placement of wire in the bladder was performed by a urologist using a standard cystoscope. Urethral dilation

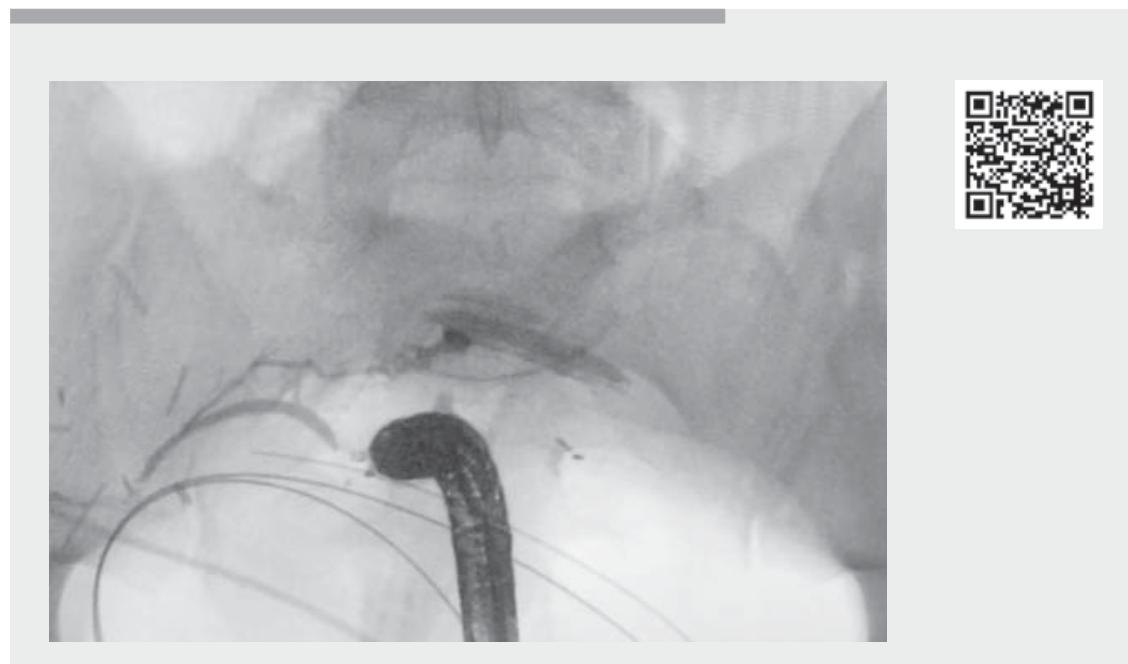

Video 1 Transurethral endoscopic retrograde pancreatography to treat complications after pancreatic transplantation.

was then performed using a biliary balloon dilator over the wire ( $\vee$ Video 1 ). Under fluoroscopy, balloon dilation was performed, with incremental increase of the balloon size up to a size equivalent to the endoscope used; in this case up to $10 \mathrm{~mm}$. Then, the balloon was used to slide and advance the endoscope. The endoscope was advanced in the bladder and a duodenovesical anastomosis, also known as pancreaticoduodenocystostomy, was identified ( $\triangleright$ Fig. 1). The donor duodenum was intubated and the major papilla located on the opposite wall from the anastomosis. The remainder of the procedure resembled ERP, with cannulation, sphincterotomy, and placement of a plastic stent for drainage of pancreatic exocrine secretions within the duodenum and bladder. At 6-month follow-up the patient is asymptomatic without any weight loss.

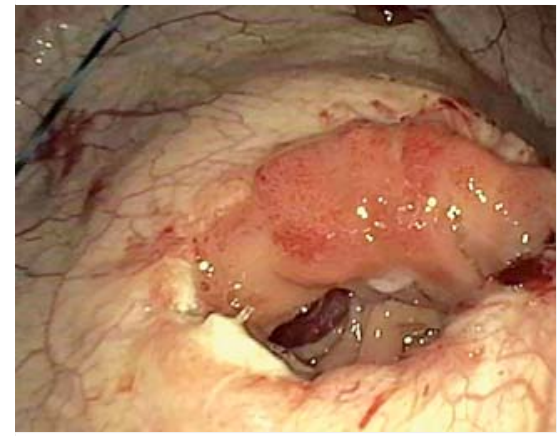

Fig. 1 Endoscopic identification of a duodenovesical anastomosis, also known as pancreaticoduodenocystostomy, in a 34-year-old man with right lower quadrant abdominal pain, fever, and leukocytosis 7 days after receiving pancreatic and renal transplants for type 1 diabetes mellitus and end-stage renal disease. 
Michel Kahaleh is a consultant for Concordia Lab and Obalon Technologies Inc. He has done research for Fuji, Pentax, Gore, Aspire, Gl Dynamics, Cook, Apollo, NinePoint Medical, and Merit. He has done research and consulting for Boston Scientific. Avik Sarkar has done consulting work for US Endoscopy and Obalon Therapeutics. Haroon Shahid has done consulting work for US Endoscopy. Amy Tyberg has done consulting work for NinePoint Medical, EndoGastric Solutions, and Obalon Therapeutics. All of the other authors have no disclosures.

The authors

Mihajlo Gjeorgjievski Abdelhai Abdelqader, Avik Sarkar, Haroon Shahid, Amy Tyberg, Michel Kahaleh

Department of Gastroenterology and Hepatology, Rutgers Robert Wood Johnson Medical School, New Brunswick, New Jersey, USA

\section{Michel Kahaleh, MD}

Department of Gastroenterology and Hepatology, Rutgers Robert Wood Johnson University Hospital, 1 RWJ Place, New Brunswick, NJ 08901, USA

mkahaleh@gmail.com

\section{References}

[1] Gruessner AC, Sutherland DER. Pancreas transplant outcomes for United States (US) and non-US cases as reported to the United Network for Organ Sharing (UNOS) and the International Pancreas Transplant Registry (IPTR) as of June 2004. Clin Transplant 2005; 19: 433-455

[2] Grochowiecki T, Gałązka Z, Madej K et al. Multivariate analysis of complications after simultaneous pancreas and kidney transplantation. Transplant Proc 2014; 46: 28062809

[3] Banga N, Hadjianastassiou VG, Mamode N et al. Outcome of surgical complications following simultaneous pancreas-kidney transplantation. Nephrol Dial Transplant 2012; 27: 1658-1663

[4] Bassi C, Dervenis C, Butturini G et al. Postoperative pancreatic fistula: an international study group (ISGPF) definition. Surgery 2005; 138: 8-13

[5] Troppmann C. Complications after pancreas transplantation. Curr Opin Organ Transplant 2010; 15: 112-118
Bibliography

Endoscopy 2022; 54: E470-E471

DOI $10.1055 / \mathrm{a}-1625-2628$

ISSN $0013-726 \mathrm{X}$

published online 27.9.2021

(C) 2021. Thieme. All rights reserved.

Georg Thieme Verlag KG, Rüdigerstraße 14,

70469 Stuttgart, Germany

\section{ENDOSCOPY E-VIDEOS}

https://eref.thieme.de/e-videos

回回 Endoscopy E-Videos is an open access online section, 回: reporting on interesting cases and new techniques in gastroenterological endoscopy. All papers include a high quality video and all contributions are freely accessible online. Processing charges apply (currently EUR 375), discounts and wavers acc. to HINARI are available.

This section has its own submission website at https://mc.manuscriptcentral.com/e-videos 